\title{
A escrita de educandas do campo sobre sentidos da prática pedagógica em escolas do campo
}

\author{
Elisvania Nunes Braz ${ }^{1}$, Nilsa Brito Ribeiro ${ }^{2}$ \\ ${ }_{1}^{1}$ Instituto Federal do Pará- IFPA. Setor Pedagógico/Ensino. Avenida Brasília s/n. Vila Permanente. Tucuruí - PA. Brasil. \\ ${ }^{2}$ Universidade Federal do Sul e Sudeste do Pará - UNIFESSPA. \\ Autor para correspondência/Author for correspondence: elisvaniabraz@yahoo.com.br
}

RESUMO. Este artigo tem por objetivo apreender, em relatórios de Estágio escritos por mulheres estudantes de um curso de Licenciatura em Educação do Campo, diferentes vozes sociais (discursos) que permeiam as representações dessas mulheres sobre o fazer pedagógico em escolas do campo. A hipótese de trabalho é que estas representações evidenciam a relação da proposta do curso com outras esferas sociais que potencializam ou desafiam a configuração teórica, metodológica e política do próprio curso, se tomadas como objeto de problematizações. Para a análise de excertos extraídos dos relatórios nos fundamentamos teoricamente na perspectiva sócio-histórica de linguagem formulada por Bakhtin e seu Círculo, além de fundamentos teóricos produzidos no domínio dos estudos da Educação do Campo. Como resultados analíticos, identificamos nos relatórios das educandas em situações de Estágio, uma forte presença de discursos que se voltam: i) para o "como fazer" pedagógico dos educadores das escolas do campo; ii) para a relação conflituosa entre os saberes escolarizados e os saberes do vivido no cotidiano dos sujeitos da aprendizagem. Essa regularidade discursiva presente nos relatórios das estudantes da licenciatura nos leva a concluir provisoriamente que os discursos dos sujeitos em formação produzidos na alternância dos tempos formativos indiciam desafios e potencialidades de uma proposta educativa aberta à multiplicidade de vozes presentes na própria proposta do curso.

Palavras-chave: Amazônia, Mulheres, Formação, Educação do Campo.

\begin{tabular}{|l|l|l|l|l|l|l|l|}
\hline Rev. Bras. Educ. Camp. & Tocantinópolis & v. 3 & n. 4 & p. 1294-1315 & set./dez. & 2018 & ISSN: 2525-4863 \\
\hline
\end{tabular}




\title{
Writings by countryside female educators on the meanings of pedagogical practice in countryside schools
}

\begin{abstract}
This article aims at understating in Internship Reports written by female students during the Degree in Countryside Education, the different social voices (discourses) that percolate these women's representation of the pedagogical practices in countryside schools. The working hypothesis is that these representations implicate the relation between the course's objectives to other social spheres that potentialize or challenge the theorical, methodological and political configuration of the degree itself if taken as object of enquiry. Analyses of excerpts from the reports were theoretically grounded on the social historical conception of language by Bakhtin and the Circle as well as on the theoretical knowledge produced in the Countryside Education studies. Analytical Results are identified in the internship reports written by female students as the remarkable presence of discourses turned to i) the pedagogical "how to" of educators in the countryside; ii) the conflicting relation between school-knowledge and the knowledge from experiences lived by the learning subjects. That discursive regularity present in the students' reports from a teaching degree leads us to the provisory conclusion that discourses by undergraduate subjects produced in the alternance of educational times point to both challenges and potentialities of an educational proposition open to multiple voices present in the very conception of the degree.
\end{abstract}

Keywords: Amazon, Women, Undergraduate Education, Countryside Education. 


\section{La escritura de las estudiantes del campo sobre los sentidos de la práctica pedagógica en las escuelas del campo}

RESUMEN. El objetivo de este artículo es analizar, en Informes de Prácticas hecho por mujeres estudiantes de un curso en Licenciatura en Educación del Campo, distintas voces en el hacer pedagógico en escuelas campesinas. La hipótesis de trabajo es que las representaciones evidencian la relación de la propuesta del curso con otras esferas sociales que potencializan o desafían la configuración teórica, metodológica y política del propio curso, si se toman como objeto de estudio fragmentos extraídos de los informes de prácticas. Nos basamos teóricamente en la perspectiva sociointeracionista de Bakhtin y su círculo, además de estudios teóricos en la Educación Campesina. Como resultados, identificamos en los informes de prácticas una fuerte presencia de discursos que se vuelven: i) para el "cómo hacer" pedagógico de los educadores de las escuelas campesinas; ii) para la relación de conflicto entre los saberes de la institución escolar y los saberes vividos en el cotidiano de los sujetos del aprendizaje. Esa regularidad discursiva se nos lleva a la conclusión, provisional, de que los discursos de los sujetos en formación construidos en la alternancia de los tiempos formativos indican desafíos y potencialidades de una propuesta educativa abierta a la multiplicidad de voces que están en la base de la propia propuesta del curso.

Palabras-clave: Amazonia, Mujeres, Formación, Educación campesina. 


\section{Introdução}

$\mathrm{Na}$ perspectiva dos estudos de Mikhail Bakhtin e seu Círculo, a linguagem é um universo simbólico no qual nascemos e nos movimentamos, de modo que todos os campos de atividade humana estão ligados a seu uso. Partimos do pressuposto bakhtiniano de que é nos processos de interação humana, nas diferentes esferas de produção da vida, que nos constituímos mediados pela linguagem. Por isso, os signos que internalizamos nos processos interacionais não têm sentidos unívocos, uma vez que eles são preenchidos de sentidos plurivocais advindos das diferentes esferas nas quais interagimos com o outro. Nas palavras de Bakhtin,

... em cada momento dado coexistem línguas de diversas épocas e períodos da vida sócio-ideológica. Existem até mesmo linguagens dos dias: com efeito, o dia sócio-ideológico e político de "ontem" e o de hoje não têm a mesma linguagem comum; cada dia tem a sua conjuntura sócioideológica e semântica, seu vocabulário, seu sistema de acentos, seu slogan, seus insultos e suas lisonjas. A poesia despersonaliza os dias na sua linguagem, já a prosa ... desarticula-os frequente $\mathrm{e}$ propositadamente, dá-lhes representantes em carne e osso e confronta-os dialogicamente em diálogos romanescos irreversíveis... as linguagens não se excluem umas das outras, mas se interceptam de diversas maneiras.. (Bakhtin/Voloshinov, 2006 ${ }^{\mathrm{i}}$, p. 98).
É desta concepção de linguagem, sempre marcada pelos processos históricos em que é produzida, que tomaremos relatórios produzidos por mulheres estudantes de duas turmas de um curso de Licenciatura em Educação do Campo (LPEC) da Universidade Federal do Sul e Sudeste do Pará (Unifesspa), para depreendermos como estas estudantes dialogam em seus relatos escritos com outras vozes sociais que vão constituindo as suas subjetividades em um contexto de formação. Assim, estabelecemos como objetivo central deste trabalho, apreender nos relatórios escritos pelas estudantes do curso o modo como elas produzem em seus discursos representações sobre o trabalho educativo nas escolas do campo e que outras vozes se entrecruzam nesse processo dialógico ou interdiscursivo.

Os relatórios analisados foram produzidos na práxis educativa na qual se assenta o curso, compreendida por dois contextos de formação que se entrecruzam: o tempo-espaço universidade e o tempoespaço localidade. Na LPEC, a vinculação desses dois tempos-espaços formativos com a realidade social e com as condições de (re) produção material dos sujeitos do campo significa a busca de superação dos limites da sala de aula e de uma real possibilidade de apreensão das 
contradições sociais que a movem. Em se tratando de educadoras do campo, é importante compreender como as subjetividades femininas experienciam sua formação na relação entre esses dois tempos formativos.

\section{Percurso metodológico}

Ancorada num arcabouço teórico que tem na relação dialógica o princípio fundante com vistas a compreender o discurso de outrem, a composição do corpus obedeceu a um percurso até chegarmos ao corpus de análise.

1. Nosso primeiro contato foi com a direção da Faculdade de Educação do Campo da Unifesspa que nos possibilitou o acesso aos arquivos da LPEC, local em que se encontram organizados os relatórios produzidos pelos estudantes do curso durante o itinerário formativo de cada turma.

2. Na segunda etapa de trabalho passamos para a seleção das turmas (2009 e 2011), cujos relatórios por elas produzidos comporiam o corpus da pesquisa. Optamos pela escolha dos relatórios das turmas de 2009 por ser a primeira turma LPEC/UNIFESSPA, na expectativa de que os relatórios pudessem nos oferecer algumas marcas caracterizadoras da história de formação da primeira experiência do curso com a orientação da produção de registros do tempo-espaço-localidade. Além disso, por ser uma turma que já havia integralizado o curso, teríamos no conjunto dos relatórios escritos o registro de todas as etapas do tempo espaço-localidade, dando-nos uma compreensão mais alargada do processo. A opção pela turma 2011 se justifica por considerarmos que entre ela e a turma de 2009 haveria um espaço de tempo razoável, permitindo-nos observar possíveis variações nos encaminhamentos de pesquisa e, consequentemente, nos modos de produção e registros do trabalho de pesquisa. Outro critério de opção por esta turma foi $\mathrm{o}$ fato de o Projeto Pedagógico ao qual estava vinculada já ter passado por algumas alterações em relação ao projeto pioneiro da turma 2009.

3. A partir do acesso aos arquivos, nosso próximo passo consistiu no levantamento de relatórios, utilizando como critério para organização dos registros dos alunos, o ano das turmas, as etapas de pesquisa e os respectivos eixos orientadores.

Nesta pesquisa assumimos a perspectiva sócio-histórica que, segundo Freitas (2003, p. 27-28), caracteriza-se pelos seguintes aspectos, dentre outros:

1. A fonte dos dados é o texto (contexto) no qual o acontecimento 
emerge, focalizando o particular enquanto instância de uma totalidade social ....

2. As questões formuladas para a pesquisa não são estabelecidas a partir da operacionalização de variáveis, mas se orientam para a compreensão dos fenômenos em toda a sua complexidade e em seu acontecer histórico. Isto é não se cria artificialmente uma situação para ser pesquisada, mas vai-se ao encontro da situação no seu acontecer, no seu processo de desenvolvimento.

Complementarmente ao que apresenta a autora, o sujeito da pesquisa (no nosso caso, estudantes da LPEC) é percebido em sua singularidade, “... mas situado em sua relação com o contexto histórico-social, portanto, na pesquisa, o que acontece não é um encontro de psiqués individuais, mas uma relação de textos com o contexto". (Freitas, 2003, p. 29).

Dessa perspectiva teóricometodológica, os relatórios escritos pelas estudantes são assumidos como discursos e, por isso mesmo, permitem leituras múltiplas, uma vez que a palavra é um elemento simbólico, portanto, não transparente: "o enunciado não diz tudo, devendo o analista buscar os efeitos dos sentidos e, para isso, precisa sair do enunciado e chegar ao enunciável através da interpretação" (Caregnato \& Mutti, 2006, p. 681). Assim, os relatórios, entendidos como discursos, são colocados em relação com as condições históricas em que foram produzidos. Um dado importante que faz parte das condições de escrita das estudantes é que seus relatos integram conhecimentos mobilizados durante as atividades realizadas no tempoespaço universidade e os saberes que vão se constituindo nas experiências desenvolvidas no tempo-espaço-localidade, sejam em escolas ou em outros espaços de atuação humana, nas comunidades em que residem. Nosso foco de análise recai, portanto, sobre sentidos que emergem da articulação que se faz entre estas duas formas de conhecimentos: os conhecimentos historicamente produzidos e sistematizados na esfera científica e os saberes da experiência produzidos na vida cotidiana dos sujeitos.

Para este trabalho, analisamos nove relatórios produzidos na confluência dos tempos e espaços de formação do curso LPEC ofertado pela Unifesspa. Da análise discursiva dos relatos emergiram temas diversos, dos quais, para este artigo, selecionamos dois, a saber: Saber docente centrado no "como fazer" e tensões entre os saberes escolarizados e os saberes do vivido. Conforme preconiza Bakhtin/Voloshinov (2006), não tomamos aqui o tema (algo individual e reiterável), meramente como conteúdo, assunto, tópico ou título principal de um texto/discurso. $\mathrm{O}$ tema é o sentido de um texto/discurso tomado na enunciação completa, como um 
todo, "único e irrepetível”, não havendo a possibilidade de se considerar a existência do tema sem significação ou o contrário. Por isso mesmo, não se toma uma palavra isolada, justamente porque "o tema da enunciação é concreto, tão concreto como o instante histórico ao qual ela pertence". (Bakhtin/Voloshinov, 2006, p. 132), como veremos adiante na seção em que realizamos a análise de sentidos em circulação nos enunciados.

\section{Tecendo considerações sobre o Curso}

De acordo com Caldart (2009), a Educação do Campo é um conceito novo e só pode ser compreendido em sua materialidade de origem, fortemente atrelada ao movimento histórico que o originou, de modo que para compreendê-la torna-se necessário localizá-la na tríade campo - políticas públicas - educação. Estes segmentos, na percepção da autora, são indissociáveis para se entender o projeto de Educação do Campo cuja origem está nos movimentos sociais e sindicais de luta pela Reforma Agrária e, principalmente, na defesa da vida e da sobrevivência no campo. Nesta direção, Caldart (2009, p. 40) argumenta que:

A Educação do Campo surgiu em um determinado momento e contexto histórico e não pode ser compreendida em si mesma, ou apenas desde o mundo da educação ou desde os parâmetros teóricos da pedagogia. Ela é um movimento real de combate ao atual estado de coisas: movimento prático, de objetivos ou fins práticos, de ferramentas práticas, que expressa e produz concepções teóricas, críticas a determinadas visões de educação, de política de educação, de projetos de campo e de país, mas que são interpretações da realidade construídas em vista de orientar ações/lutas concretas.

Com a consolidação de várias experiências acadêmicas apoiadas pelo Programa Nacional de Educação na Reforma Agrária (Pronera) e pelos movimentos sociais e sindicais do campo, e ainda com a vinculação, em 2007, da Universidade Federal do Pará (UFPA) ${ }^{\mathrm{ii}}$ ao Programa do Governo Federal de Apoio a Planos de Reestruturação e Expansão das Universidades Federais Brasileiras (REUNI) ${ }^{\mathrm{iii}}$, a UFPA/Campus de Marabá passou a ofertar o primeiro curso de Licenciatura em Educação do Campo das regiões Sul e Sudeste do Pará, em 2009. Nas notas iniciais de apresentação do livro Práticas contra-hegemônicas na formação de educadores: reflexões a partir do curso de Licenciatura em Educação do Campo do sul e sudeste do Pará (2014), os organizadores, em alusão às experiências de formação de educadores do campo, destacam: 
O acúmulo conquistado por essa construção histórica possibilitou a concepção do curso de Licenciatura Plena em Educação o Campo (LPEC), que, desde 2009, tem ofertado uma turma-ano. Ainda que a institucionalização do curso no interior da Unifesspa represente a convergência a uma política nacional de Educação do Campo, ela responde, mais concretamente, às demandas do movimento de Educação do Campo na região, especialmente como parte da luta pela Reforma Agrária. (Santigo, Souza \& Ribeiro, 2014, p. 11).

Mais do que a oferta de uma nova modalidade de licenciatura, a LPEC é uma proposta de formação que nasceu dos/com os sujeitos do Campo (Caldart, 2011), tal como ocorreu em outras regiões do país. Nas regiões Sul e Sudeste do Pará, o curso se apresenta como parte de uma luta mais ampla na qual se insere o projeto contrahegemômico de formação de educadores (as) do campo. Sob a compreensão do compromisso do curso com a luta social, a sua matriz curricular se estrutura em quatro áreas de conhecimento "tendo o exercício e a busca da interdisciplinaridade como princípio pautado para a formação dos educandos". (Unifesspa, 2014, p. 15). São elas, Ciências humanas e Sociais (CHS), Ciências Agrárias e da Natureza (CAN), Letras e Linguagens (LL) e Matemática (MAT).

A opção pela formação por área de conhecimento é considerada uma importante estratégia dos cursos de licenciatura por expandir a oferta das séries finais do ensino fundamental e do ensino médio no campo, considerando que em muitas localidades o ensino restringe-se às séries iniciais do Ensino Fundamental. No contexto da ampliação do acesso ao ensino, destaca-se que “... a intencionalidade maior é a de contribuir com a construção de processos capazes de desencadear mudanças na lógica de utilização e de produção de conhecimento no campo". (Molina, 2015, p. 153).

Essa lógica está relacionada ao "processo de desestabilização de uma ordem dada e de desnaturalização de uma forma curricular (a disciplinar) que é histórica, mas passa a ser assumida como a única possível no trabalho com o conhecimento". (Caldart, 2011, p. 141). A crítica a esta lógica promove o repensar, tanto da formação do educador, como de sua atuação docente nas localidades. Para Molina e Sá,

... no caso da proposta de formação por áreas, não são as disciplinas o objetivo central do trabalho pedagógico com o conhecimento. Este trabalho se dirige a questões da realidade como objeto de estudo, tendo como base a apropriação do conhecimento científico já acumulado. Colocam-se, então, indagações epistemológicas sobre a própria concepção de conhecimento, de ciência e de pesquisa. Indaga-se de que forma o trabalho pedagógico pode garantir o movimento entre apropriação e produção do conhecimento e a articulação entre 
conhecimento e processo formativo como um todo permanente entre o conhecimento que a ciência ajuda a produzir e as questões atuais da vida. Os fenômenos da realidade atual precisam ser estudados em toda a sua complexidade, tal como existem na realidade, por meio de uma abordagem que dê conta de compreender totalidades nas suas contradições, no seu movimento histórico. (Molina \& Sá, 2012, p. 471-472).

Na LPEC, o trabalho com áreas de conhecimento fundamenta-se na pedagogia da práxis e na valorização da experiência dos sujeitos como formas concretas de produção e geração de conhecimentos, com vistas à transformação da realidade (Unifesspa, 2014). Mediante a compreensão da práxis como ação reflexiva do conhecimento construído e da associação teórico-prática no fazer docente, o curso assume como princípios pedagógicos e éticos: a formação contextualizada; a realidade e as experiências das comunidades do campo como objeto de estudo e fonte de conhecimentos; a pesquisa como princípio educativo; a indissociabilidade teoriaprática; o planejamento e ação formativa integrados às áreas de conhecimento; os educandos como sujeitos do conhecimento e a produção acadêmica para a transformação da realidade.

$$
\mathrm{O} \text { projeto Pedagógico da }
$$
LPEC/Unifesspa anuncia, em suas diretrizes curriculares, a articulação entre os saberes inseridos no contexto das populações do meio rural, sem, no entanto, negligenciar as teorias e metodologias presentes no meio acadêmico. Acredita-se que, pautado nestas diretrizes, o curso promove a sua efetividade.

Essa vinculação da formação ao espaço de vida do campo se materializa e se organiza na LPEC através da alternância de dois tempos da formação que se integram, dialeticamente, para promover a formação pedagógica de educadores e educadoras do campo. São eles: o Tempoespaço Universidade (TEU) e o Tempoespaço Localidade (TEL). ${ }^{\text {iv }}$ Estes temposespaços são entendidos "como territórios de saberes balizados por disputas, conflitos, relações de poder inerentes à construção histórica do ser social". (Costa \& Monteiro, 2014, p. 117).

\begin{abstract}
A organização dos tempos e espaços em alternância (Tempo Escola e Tempo Comunidade) parte do princípio de que escola e comunidade são tempos/espaços para construção e avaliação de saberes e que, portanto, é necessário superar a perspectiva de que a escola é lugar da teoria e a comunidade é lugar da aplicação/transformação. No curso, o estudante desenvolve um tempo de estudos na universidade e outro nos locais de moradia/trabalho. No sentido adotado não há distâncias durante a formação e sim espaços/tempos diferenciados de produção e socialização de saberes. (Antunes-Rocha, 2010, p. 02).
\end{abstract}


O Tempo-espaço Universidade comporta Seminários de socialização do Tempo-espaço Localidade e "estudos dos conhecimentos pedagógicos e da educação do campo voltados à formação da docência” (Unifesspa, 2014, p. 29), materializados em estudos de disciplinas do Núcleo Comum e do Núcleo Específico.

O Tempo-espaço Localidade é o momento em que ocorre a imersão dos (as) educandos (as) em suas localidades de origem para a prática da pesquisa local, buscando apreender o contexto social, educacional, político e cultural, a partir da prática investigativa. Este tempo-espaço agrega diferentes atividades no itinerário da formação. De acordo com o PP, estas atividades dividem-se em dois tipos: Pesquisa Sócio-Educacional e Estágiodocência. Segundo a proposta curricular do curso, o Tempo-espaço Localidade é:

O tempo das práticas de pesquisa social e educacional, configurando-se como momento de investigação acadêmica sobre o cotidiano pedagógico das escolas rurais e das comunidades em que elas se situam. É o momento de levantamento de dados e da vivência de experiências sócioeducativas junto à escola e a comunidade de modo que permitam a construção de reflexões sobre a realidade e os processos pedagógicos que no campo se desenvolvem. (Unifesspa, 2014, p. 30).
Os tempos formativos da LPEC TEU e TEL- são balizados por cinco eixos temáticos (Sociedade, Estado, Movimentos Sociais e Questão Agrária; Educação do Campo; Saberes, Cultura e Identidades; Sistemas familiares de produção; Campo, Territorialidade e Sustentabilidade), distribuídos em oito etapas. De acordo com a proposta formativa, a opção por eixos favorece a superação disciplinar e articula áreas de conhecimento diferentes. Através de três núcleos distintos e interrelacionados - estudo comum, estudo específico e atividades livres ou complementares -, o percurso formativo se consolida ao longo de oito etapas de tempos e espaços formativos, sob a orientação temática dos eixos acima mencionados.

Os relatórios, material de análise neste estudo, são produzidos no movimento de alternância desses dois tempos (Tempo-espaço Universidade e Tempo-espaço Localidade) e sempre orientados pelas reflexões produzidas nestes eixos. Por isso, a apreensão de sentidos produzidos nos relatos das estudantes do curso deve levar em consideração o contexto propiciado pelas reflexões produzidas nos eixos. No item seguinte, passaremos à análise de enunciados extraídos dos relatórios das estudantes, dentro de uma abordagem 
dialógica da linguagem, justamente porque ela propicia a mobilização de diferentes vozes presentes em um mesmo discurso e os embates sociais aí produzidos. Para isso, antes das análises, traremos breves notas acerca da teoria do dialogismo bakhtiniano, na qual se assentam as análises.

\section{Nos discursos das educandas outras vozes ensaiam diálogos}

Para efeito de organização e desenvolvimento das análises, reunimos os enunciados em temas sob a compreensão de que o sentido/tema constitui a unidade de um todo complexo da cadeia discursiva em circulação na sociedade. O tema, para Bakhtin, não tem qualquer correspondência com levantamento aleatório de assuntos para serem debatidos, como tradicionalmente ocorre nas práticas de redações escolares. Na percepção do autor, o tema emerge dos discursos dos sujeitos na sua relação com a história, dentro de uma dada esfera de atividade humana, por isso mesmo, não é um dado a priori aos discursos, uma vez que ele só pode ser apreendido na relação do pesquisador com o que é dito em uma dada conjuntura.

Assim, neste processo investigativo, concebemos o que é dito/escrito nos relatórios como discursos/enunciados mobilizados por representações que as estudantes em formação produzem sobre o mundo, sobre si e sobre o outro, a partir da posição social e ideológica que ocupam no mundo. A escrita das estudantes, concebida em sua dimensão discursiva, compõe a cadeia enunciativa da ininterrupta atividade de produção do conhecimento destas mulheres, ao longo do processo formativo, mesmo antes de chegarem à escola. Os sentidos veiculados nos relatos serão captados sempre na sua relação dialógica, entendendo que nenhum discurso circula no mundo sem trazer em si o eco de outras alteridades, nenhum discurso é indiferente às diferentes vozes sociais com as quais dialoga sob a forma de resposta, adesão, refutação, complementação, questionamento, recusa etc.

Seguindo o percurso metodológico sugerido por Bakhtin (2006), no que concerne ao trabalho com a linguagem, nossa primeira aproximação é com as condições sócio-históricas em que se materializa um Projeto de Educação do Campo, devendo ser considerado o contexto político, educacional e cultural dos sujeitos que se encontram envolvidos em tal projeto, conforme já discutimos no item anterior; a segunda aproximação se dá com as esferas em que os relatórios foram produzidos, considerando a esfera científica/universitária, os ambientes de 
pesquisa na comunidade, assim como os espaços de trabalho das estudantes; por fim, chegaremos à materialidade dos textos produzidos para apreendermos o movimento dos discursos.

$\mathrm{Na}$ medida em que as estudantes retomam os saberes advindos das comunidades, dando-lhe estatuto de pesquisa, já realiza um processo dialógico com os saberes produzidos na academia, objetivando-o no processo de aprendizagem e na construção de novos conhecimentos. Neste sentido, opera um complexo movimento discursivo regido pelo princípio dialógico constitutivo dessa articulação que transita entre os saberes sistematizados (tempo-espaço universidade) e os saberes locais/sociais (tempo-espaço localidade). Cada um destes tempos-espaços é constituído de ideologias que lhes são próprias e reveladoras de tensões e conflitos.

Nesta compreensão, adotamos o entendimento bakhtiniano de que as palavras, inevitavelmente, ao serem ditas, já se encontram povoadas por outras vozes, de forma que todo discurso, ao retomar discursos já-ditos mantém-se aberto à incorporação de novas vozes, num processo interativo entre o discurso que antecede o dizer e o discurso em devir. Por isso, assumimos o pressuposto de que as palavras enunciadas pelas estudantes em seus relatos disputam sentidos diversos e é na disputa de sentidos que podemos perceber sinais da luta ideológica.

Os enunciados foram agrupados em dois temas que compareceram com maior regularidade nos relatórios das estudantes, configurando sua relação com a prática educativa nas escolas do campo. Estes dois temas são: Saber-docente centrado no como fazer; tensões entre os saberes escolarizados e os saberes do vivido.

\section{Saber docente centrado no "como fazer"}

Os enunciados reunidos sob esta temática remetem a uma forte atenção das estudantes da LPEC a questões concernentes a metodologias de ensino nas escolas do campo. A atenção dispensada a esta dimensão do trabalho docente, ora assume um tom positivo, ora negativo. Nossa atenção se volta a esses discursos para melhor compreendermos que concepção de formação pode estar subjacente a um discurso em que a metodologia de ensino, ou seja, o como fazer, muitas vezes sobrepõe-se ao que fazer, por que fazer e com quem fazer. Que histórias de formação estão na base desses discursos?

\section{E1 ${ }^{v}$ :}

Apesar do conteúdo ser o único instrumento de base do professor é interessante destacar que o trabalho 
de socialização do mesmo dar-se sob um cuidado de pensar o cotidiano dos sujeitos de forma que os alunos possam refletir de maneira crítica com essa fundamentação teórica que se faz necessária para pensar a realidade a qual estão envolvidos. Ou seja, há um esforço do professor de contextualizar o conteúdo trazendo exemplos da mídia, exemplos cotidianos que perpassa pela vida dos alunos, principalmente, quando se trata da juventude, dialogando com suas experiências de vida e com os conhecimentos prévios dos alunos de forma interdisciplinar usando elementos de outras disciplinas na construção do pensamento filosófico. (I. S. S. S. / VI TEL, 2014 ${ }^{\mathrm{vi}}$ ).

\section{E2:}

Embora a professora usasse somente o livro didático nas aulas, em três momentos ela trouxe exemplos da atividade para a realidade dos alunos, nestes momentos houve uma participação maior dos alunos, dando exemplo, também esses exemplos foram dois ou três, logo a professora pediu para os alunos responderem as duas questões do livro, neste momento finalizou o diálogo interativo na sala. (M. E. C. G./IV TEL, 2011).

\section{E3:}

Seguindo o conteúdo e o plano de aula, o professor quando vai trabalhar texto começa com a leitura oral do mesmo, introduz perguntas reflexivas, depois passa para as questões envolvendo interpretação propostas no livro, onde os alunos se sentam juntos e vão copiar e responder, na maioria das vezes é assim que acontece. Com o estudo da gramática, a metodologia é quase a mesma, estudo dos conceitos do conteúdo após a explicação por meio de exemplos, realizar o exercício, vem a atividade individual, realizada na sala, onde os alunos passam as perguntas do livro para o caderno e em seguida respondem as mesmas. Há algumas vezes que as questões do livro são substituídas por questões da autoria do professor. Enquanto os alunos respondem silenciosamente as questões, o professor sempre prepara algo para depois, e acabado o tempo as questões são corrigidas ou deixadas para a aula seguinte. Em linhas gerais esse é o modo como as aulas seguem os três dias da semana. (A. C. S. D. / IV TEL, 2011).

\section{E4:}

Observando a rotina dos alunos em sala de aula, percebi que a professora estava ministrando uma aula que tinha como principais materiais de apoio o livro didático, o quadro e o giz. Geralmente os professores escrevem os conteúdos no quadro, em seguida explicam, os alunos escrevem e respondem as atividades e depois as desenvolvem para os professores corrigirem. (M. R. J./III TEL, 2009).

A atividade curricular que gerou a escrita dos relatórios de onde foram extraídos os enunciados de 1 a 4 é denominada de Estágio-docência de Pesquisa Observação Sistemática. Tal atividade consiste na prática de observação e registro de saberes escolares, metodologias, desenvolvidos nas escolas do campo. Embora haja uma diversidade de questões a serem observadas pela estudante da LPEC durante observações e registros de estágios, os relatórios mostram que a ênfase das estudantes recai, quase sempre, sobre a metodologia de ensino do professor da escola. Esse olhar detido sobre a metodologia de ensino já produz 
um efeito que nos faz perguntar por sentidos a ele relacionados, ou seja, é preciso perguntar pelas condições históricas que orientam as estudantes a elegerem como foco de suas observações a metodologia adotada pelo/a professor/a em sala de aula.

Se atentarmos para a materialidade dos enunciados 1, 2, 3 e 4, veremos que as professoras em formação observam a prática do/da professor/a, questionando-a, confrontando-a e avaliando-a segundo o que consideram como prática pedagógica transformadora e condizente com as necessidades específicas dos sujeitos do campo.

$\mathrm{Na}$ representação das estudantes, o/a professor da escola básica do campo é caracterizado/a como aquele/a que: 1) se limita ao uso do quadro, do giz e do livro didático como únicos suportes pedagógicos para realizarem suas aulas (percebi que a professora estava ministrando uma aula que tinha como principais materiais de apoio o livro didático, o quadro e o giz); 2) poucas vezes utiliza exemplos do cotidiano dos estudantes ou a pesquisa como fonte de produção de conhecimento (Apesar do conteúdo ser o único instrumento do professor; pouco incentivando a investigação ou a pesquisa e a princípio não vejo atividades trabalhadas envolvendo projetos ou ações em grupo, também não observei a exploração dos saberes locais do tipo: Histórias orais, conhecimentos locais ou contos populares); 3) segue uma linearidade na aplicação das atividades didáticas (Geralmente os professores escrevem os conteúdos no quadro, em seguida explicam, os alunos escrevem e respondem as atividades e depois as desenvolvem para os professores corrigirem).

Essas representações, de cunho negativo, são encontradas em muitos escritos das estudantes da LPEC. Ao mesmo tempo, essas avaliações delineiam as representações das estudantes sobre o que seja um "bom educador" do campo. como no trecho do enunciado 1: é interessante destacar que o trabalho de socialização do mesmo dar-se sob um cuidado de pensar o cotidiano dos sujeitos de forma que os alunos possam refletir de maneira crítica com essa fundamentação teórica que se faz necessária para pensar a realidade a qual estão envolvidos... Essa mesma observação positiva se verifica no enunciado 2: ... ela trouxe exemplos da atividade para a realidade dos alunos.

Nos fragmentos destacados a centralidade do olhar das educandas está no fazer metodológico. Tal centralidade é atravessada por sentidos que por vezes colocam na adoção desta ou daquela 
metodologia o sucesso ou o fracasso do processo de ensino e aprendizagem. Ao se colocar na cena enunciativa propostas que visam melhorar o processo educativo em observação, as estudantes parecem querer se distanciar da imagem negativa do professor observado, como também procuram (re) construir para si mesmas a imagem de educadoras comprometidas com a história de vida dos sujeitos do campo.

Os enunciados firmados no discurso da ação (o professor fez isso ou não fez aquilo), em detrimento da tentativa de compreender o porquê de tais ações, nos impulsiona a colocar em questão o debate sobre a Pedagogia das Competências (Ramos, 2012), como forte tendência no campo da formação de professores e bastante difundida nos documentos oficiais que orientam a educação no Brasil. Retomar o discurso do outro, ou seja, das competências, torna-se necessário, num curso que busca superar os discursos da competência pedagógica, uma vez que analisar os discursos significa considerar as dimensões social e histórica dos textos para examinar tanto os processos de constituição discursiva quanto as representações que deles emergem.

$\mathrm{Na}$ década de 1990, o termo competências ganhou força, principalmente a partir das reformas educacionais ocorridas no Brasil para atender às demandas do processo de reestruturação produtiva do capital. Nessa concepção pragmática da docência, a ênfase recai sobre a valorização das subjetividades e diferenciação individual. Nesse sentido, os discursos das estudantes, ao destacarem o "como fazer" como principal dimensão da formação podem incorrer na lógica das competências, principalmente se tais enunciados não forem tomados no próprio processo formativo das estudantes como objeto de problematização. Assim, o diálogo entre as diferentes vozes sustentadoras do discurso possibilitado pelas reflexões realizadas pelas estudantes da LPEC abre espaço para flagrarmos concepções e representações pedagógicas nas quais se assentam os processos educativos desde a escola básica.

Obviamente, que os discursos das estudantes dialogam com o discurso acadêmico da LPEC, o qual tem feito a crítica contundente a concepções de ensino que tornam o livro didático única fonte de (in) formação do professor da escola básica. Nessa relação dialógica, é possível captar no discurso das estudantes que o livro didático é o "vilão" do processo de ensino e aprendizagem das escolas do campo, ora retirando a autonomia do professor, ora impedindo uma abordagem mais ampla do contexto histórico, político 
e social, justamente porque não tem como contemplar os temas da vida concreta dos sujeitos da formação.

As estudantes se ancoram na formação acadêmica para elaborar suas percepções do outro e, nessa mesma relação, deixam entrever que a Educação do Campo ainda tem um percurso longo a ser feito no sentido de problematizar a construção de novas identidades docentes nas escolas do campo. Neste sentido, os discursos convergem para outra temática a qual denominamos de tensões entre os saberes escolarizados e os saberes do vivido com o intuito de mostrar, nos discursos, as expectativas das estudantes da LPEC em relação à transformação da escola e dos processos educacionais vivenciados e praticados nas localidades.

\section{Tensões entre os saberes escolarizados e os saberes do vivido}

Chamamos a atenção nesta temática para a tensão denunciada pelas estudantes, em seus discursos, quanto ao silenciamento dos saberes dos sujeitos em detrimento dos saberes escolares. Aqui, vemos a presença de uma relação interdiscursiva da estudante da LPEC com o projeto de Educação do Campo, na defesa da relação indissociável entre conteúdos sistematizados na Universidade e saberes cotidianos dos sujeitos que adentram a escola.
Os enunciados 5 e 6, apesar de terem sido produzidos por estudantes de turmas diferentes, inserem-se no mesmo eixo de conhecimentos: Saberes Culturas $e$ Identidade. A pesquisa de ambas as turmas tinha como tema de abordagem "os saberes escolares na prática docente e currículo escolar, visando: observar os saberes escolares na educação rural, enfocando as relações educativas e os conteúdos do currículo praticado...”. (Unifesspa, 2014, p. 42).

\section{E5:}

Dentro do processo pedagógico da escola pude perceber as dificuldades dos professores em relação ao planejamento de ensino, os mesmos seguem os livros didáticos para a seleção e organização dos conhecimentos utilizados na formação dos estudantes, sem atentar para as implicações curriculares resultantes dessa atitude, uma vez que esse material didático está longe da realidade desses alunos. (C. M. da C./ III TEL, 2009).

\section{E6:}

Os saberes que a escola apresenta aos alunos é unicamente aqueles escritos no livro didático, não existe um cruzamento dos textos com a realidade dos sujeitos, a valorização da cultura e conhecimentos empíricos de cada aluno não é levada em consideração na sala de aula. Nas aulas o educador utiliza somente o livro didático e o caderno dos educandos para cópia e resolução de atividades, os meios de avaliações são únicos, os alunos respondem todas as questões e tiram notas boas, se não conseguem responder as questões conforme o que o educador 
corrigiu para ele, os alunos não aprenderam nada ou não é capacitado para ser promovido para outra série/ano. (L. S. S. / IV TEL, 2011).

Sabemos que o livro didático é um recurso do qual o professor poderá lançar mão durante $\mathrm{o}$ processo de ensino $\mathrm{e}$ aprendizagem. No entanto, sabe-se, também, que o processo de produção de livros didáticos, desde seu surgimento, tem sido questionado por sua produção atender, por vezes, interesses editoriais que vão na contramão da diversidade de orientações pedagógicas postas em questão quando se trata de diversidade educacional e cultural.

Silva (2012), ao discutir sobre a fetichização do livro didático, ressalta como esse recurso pedagógico, ao longo dos anos, tornou-se supervalorizado na cultura escolar brasileira. Segundo o autor, “esse status alcançado nas representações sociais pelos livros didáticos é resultado de uma complexa trajetória histórica, uma significativa relevância econômica, e de contornos ideológicos e políticos, sobretudo no período republicano brasileiro". (Silva, 2012, p. 803).

Utilizar o livro didático como único apoio ao trabalho do professor sem atentar para as implicações curriculares resultantes dessa atitude, conforme registra a estudante no enunciado 5, produz limitações ao processo formativo, de modo que os sujeitos da formação são impedidos de problematizar suas realidades locais e nelas interferirem. Restringir a construção do conhecimento a uma única orientação já prevista no livro didático, a partir de um conteúdo unificado e homogeneizador, torna-se um empecilho para o desenvolvimento de projetos educativos com enfoque nas realidades locais. Ter o livro didático como único desencadeador de conhecimentos é relegar as escolas do campo à precariedade. Assim, não podemos perder de vista que essas limitações das condições materiais das escolas do campo "evidenciam a contradição entre o discurso do direito, marco jurídico e a política educacional específica”. (Silva, 2009, p. 348).

Além de o livro didático figurar como único instrumento desencadeador da aprendizagem, os enunciados ainda denotam a concepção educacional preponderante nas práticas metodológicas observadas nas escolas do campo pesquisadas pelas estudantes, concepção cuja figura central é o professor.

\section{E7:}

$\mathrm{O}$ educador ministra suas aulas baseadas somente no livro didático, não tem pesquisas bibliográficas nem aproximação dos conteúdos com a realidade dos sujeitos, os alunos não discutem os textos que são lidos durante as aulas, não falam, só ouvem o que o professor lê ou fala. A sistematização dos conteúdos é por meio de escrita de atividade e 
correção da mesma, os alunos não falam não tem voz ativa nas socializações das atividades até porque se torna muito difícil o entendimento dos textos sem algo palpável.

Durante a observação na sala de aula na disciplina de História foi possível perceber que não há diálogo entre educador-educando, a metodologia sempre consiste em entrar na sala de aula alertar os educandos sobre o conteúdo a ser estudado, ordenar que os educandos abram o livro didático nas páginas indicadas, e realizar leituras individuais e em voz baixa, e responder a atividade, pois na próxima aula o educador irá corrigir e "dar o visto", não se atentando se a questão está certa ou errada. (L. S. S./III TEL, 2011).

Como se pode observar, o enunciado 7 traz algumas marcas representativas de um discurso que delineia a permanência da figura de um professor como único detentor do saber. Aqui, o ensino livresco se caracteriza como silenciador da relação escola-trabalho mediada pela pesquisa. Prevalece, nesta forma de ensino e aprendizagem:

a)

O professor como único

detentor do saber: ... os alunos não discutem os textos que são lidos durante as aulas, não falam, só ouvem o que o professor lê ou fala ...

b) $\mathrm{O}$ ensino mecânico e livresco: ... O educador ministra suas aulas baseadas somente no livro didático

c) A aplicação da finalidade do processo educacional: ... $n a$ próxima aula o educador irá corrigir e "dar o visto", não se atentando se a questão está certa ou errada ...

As sequências discursivas destacadas no enunciado 7 apontam para práticas pedagógicas centradas numa concepção de ensino cujo foco incide na figura do professor como único detentor do saber, enquanto os alunos, no outro polo do processo, se posicionam como recebedores e reprodutores do suposto saber "depositado" por seu professor. Desta forma, os alunos não discutem os textos que são lidos durante as aulas, não falam, só ouvem o que o professor lê ou fala. Esse parece ser um quadro que a Educação do Campo se propõe a superar, desenvolvendo uma outra lógica formativa. Os discursos das estudantes tocam em um estado de coisas desafiador para uma proposta emancipadora. Contrariando a escola tradicional, os discursos sugerem um novo projeto educacional no qual a metodologia de ensino esteja alinhada com uma proposta humanizadora de formação, enquanto parte de um projeto político mais amplo.

Sem perder de vista a importância da articulação dos saberes acadêmicos com o campo social de vida dos estudantes e as representações pedagógicas que estão na base da teia discursiva, municiadas pelas 
contribuições das leituras realizadas no percurso educativo, as estudantes ampliam seus horizontes de análise evocando discursos da academia para corroborar suas reflexões, numa relação dialógica entre o mundo do conhecimento e o mundo do vivido.

Há outras marcas neste enunciado que denotam a ineficácia da mera transmissão de conhecimentos, baseada na relação docente unilateral e autoritária: $a$ metodologia sempre consiste em entrar na sala de aula alertar os educandos sobre o conteúdo a ser estudado, ordenar que os educandos abram o livro didático nas páginas indicadas, e realizar leituras individuais e em voz baixa, e responder a atividade, pois na próxima aula o educador irá corrigir e dar o visto. É importante destacar nesse discurso o silenciamento da alteridade: os alunos não falam não tem voz ativa nas socializações das atividades até porque se torna muito difícil o entendimento dos textos sem algo palpável. Ambos, professor e alunos, colocados neste cenário, perdem a oportunidade de, dialogicamente, compartilhar saberes. Essa parece ser a questão apontada e contraposta pelas estudantes em seus relatos. Na percepção de Freire, o diálogo é uma prática necessária ao professor mediador, no sentido de articular as experiências dos alunos com o seu mundo, com sua existência.

\begin{abstract}
... o diálogo é uma exigência existencial. E, se ele é o encontro em que se solidarizam o refletir e o agir de seus sujeitos endereçados ao mundo a ser transformado e humanizado, não pode reduzir-se a um ato de depositar ideias de um sujeito no outro, nem tampouco tornar-se simples troca de ideias a serem consumidas pelos permutantes. (Freire, 2005, p. 91).
\end{abstract}

$\mathrm{Na}$ complexidade do processo educativo, fortemente marcado pelas variáveis pedagógicas e sociais que o envolvem, as estudantes da LPEC compreendem que esse não pode ser efetivamente conduzido fora da interação dialógica entre escola e vida, escola e sociedade, tal como um projeto emancipador exige.

\section{Considerações Finais}

A partir do pensamento bakhtiniano, especialmente da dialogia entre os discursos, ou seja, da correspondência de um discurso a outro, a análise dos relatórios nos permitiu apreender temas que se traduzem em vozes que participam do processo formativo das estudantes, apontando tanto para a vida que adentra a universidade, reclamando novos objetos de formação quanto para as relações com a academia, sugerindo novas fronteiras a serem transgredidas. 
Ao assumirmos o conceito de dialogismo como estruturante do processo de construção do conhecimento, foi possível apreender no discurso das estudantes sua relação com as bases teórico-metodológicas do curso, as quais lhes propiciam, no processo de avaliação do outro, a percepção de que a escola básica do campo ainda mantém fortes vínculos com a tradição pedagógica hegemônica e homogeneizadora. A avaliação inscrita nos relatos das estudantes da LPEC sugerem ser este um domínio que merece ser melhor investigado e problematizado por um projeto de educação emancipadora. Os relatórios vêm se constituindo em material de pesquisa importante para o início de um processo investigativo nesta direção.

No entanto, ainda que as observações das estudantes produzam deslocamentos importantes da imagem ocupada pelo professor das escolas para uma imagem alinhada com os princípios da Educação do Campo, há contradições que devem vir para a cena do debate sobre a formação. Por exemplo, o olhar das estudantes voltado, quase exclusivamente, para a metodologia de ensino enquanto um ponto fixo do processo educacional, merece ser problematizado, pois a escola do campo é muito mais do que escola, de modo que outras dimensões do processo devem também ocupar a cena discursiva, sob pena de cairmos na pura e simples instrumentalização da ação do professor das escolas do campo.

Os discursos das estudantes, abrem, portanto, duas vias de investigação que são intercomplementares: a tradição escolar homogeneizante presente nas escolas do campo e a história de formação das estudantes da LPEC centrada no como fazer da escola. Ambas vertentes apontam para a necessidade de maior problematização do curso.

\section{Referências}

Antunes-Rocha, M. I. (2010). Licenciatura em educação do campo. In Oliveira, D. A., Duarte, A. M. C., \& Vieira, L. M. F. (Orgs.) Dicionário: trabalho, profissão e condição docente. Belo Horizonte: UFMG/Faculdade de Educação. CDROM.

Arroyo, M. G. (1999). A educação básica e o movimento social do campo. In

Fernandes, B. M. (Org.). A Educação Básica e o Movimento Social do Campo (pp. 10-38). Brasília, DF: Articulação Nacional Por Uma Educação Básica do Campo.

Bakhtin, M. (V. N. Volochínov). (2006). Marxismo e Filosofia da Linguagem. 12. Ed. São Paulo: Hucitec.

Caldart, R. S. (2011). Licenciatura em Educação do Campo e projeto formativo: qual o lugar da docência por área. In

(Org.). Caminhos para transformação da escola: reflexões desde práticas da Licenciatura em Educação do Campo (pp. 127-154). São Paulo: Expressão Popular. 
(2009). Educação do Campo: notas para uma análise de percurso. Trabalho, Educação e Saúde, (7), 35-64.

Caregnato, R. C. A., \& Mutti, R. (2006). Pesquisa qualitativa: análise de discurso versus análise de conteúdo. Texto Contexto Enferm, 679-684. Recuperado de: http://www.scielo.br/pdf/tce/v15n4/v15n4a 17 Acesso em 03 de março de 2017.

Costa, E. M., \& Monteiro, A. L. (2012). Procampo: uma política de formação inicial para o docente do campo. In Anais XVI ENDIPE - Encontro Nacional de Didática e Práticas de Ensino. UNICAMP - Campinas.

Freire, P. (2005). Pedagogia do Oprimido. 17. ed. Rio de Janeiro: Paz e Terra.

\section{(1981). Ação Cultural para a} liberdade e outros escritos. Rio de Janeiro: Paz e Terra.

Freitas, M. T. (2003). A perspectiva sóciohistórica: uma visão humana da construção do conhecimento. In Freitas, M. T., Jobim, S. S., \& Kramer, S. (Orgs.) Ciências humanas e pesquisa: leitura de Mikhail Bakhtin (pp. 26-38). São Paulo, Cortez.

Molina, M. C., \& Sá, L. M. (2010). A Licenciatura em Educação do Campo da Universidade de Brasília: Estratégias Político-Pedagógicas na Formação de Educadores do Campo. In Molina, M. C., \& Sá, L. M. S. (Orgs.). Licenciaturas em Educação do campo: Registros e reflexões a partir das experiências Piloto (pp. 3562). Belo Horizonte: Autêntica Editora.

(2015). A educação do campo e o enfrentamento das tendências das atuais políticas públicas. Educação em Perspectiva, (6) 2, 378-400.

Ramos, M. (2012). Escola Unitária. In Caldart, R. S., et. al. (Orgs.). Dicionário da Educação do Campo (pp. 343-349). São
Paulo: Escola Politécnica de Saúde Joaquim Venâncio, Expressão Popular.

Silva, I. S., Souza, H., \& Ribeiro, N. B. (2014). Apresentação. In . (Orgs.). Práticas contra-hegemônicas na formação de educadores: reflexões a partir do curso de Licenciatura em Educação do Campo do Sul e sudeste do Pará (pp. 11-19). Brasília: MDA.

Silva, M. A. (2012). A fetichização do livro didático no Brasil. Educ. Real., 37(3), 803-821, Recuperado de: http://www.scielo.br/pdf/edreal/v37n3/ 06.pdf. Acesso em: 07 de julho de 2017

Unifesspa. (2014). Projeto Pedagógico do Curso de Licenciatura em Educação do Campo, Marabá.

\footnotetext{
i 1929 é a data da primeira edição de Marxismo e Filosofia da Linguagem. A edição consultada é de 2006. Devido à polêmica gerada em torno da autoria desta obra, optamos pela dupla referência Bakhtin/Voloshinov.

ii Até junho de 2013, o Campus Universitário de Marabá, hoje Unifesspa, esteve vinculado à UFPA.

iii O Reuni foi instituído pelo Decreto Presidencial 6.096, de 24 de abril de 2007 e integra o conjunto de ações do Governo Federal no Plano de Desenvolvimento de Educação no âmbito do MEC.

iv Algumas instituições adotam Tempo-escola e Tempo-comunidade. Apesar de termos percebido o aparecimento destes termos em algumas passagens do Projeto Pedagógico da LPEC/Unifesspa, optamos pelos termos tempo-espaço universidade e tempo-espaço localidade por se apresentarem, na proposta, de forma mais recorrente.
}

${ }^{v}$ Convencionamos identificar os recortes extraídos dos relatórios de Enunciados, numerados conforme a ordem em que forem apresentados (E1, E2, E3, sucessivamente).

${ }^{\text {vi }}$ Identificamos cada estudante com as iniciais do seu nome, seguidas do tempo-espaço localidade (TEL) e o ano de ingresso da turma. 


\section{Informações do artigo / Article Information}

Recebido em : 30/04/2018

Aprovado em: 25/05/2018

Publicado em: 23/12/2018

Received on April 30th, 2018

Accepted on May 25th, 2018

Published on December 23th, 2018

Contribuições no artigo: As autoras foram responsáveis pela elaboração, análise e interpretação dos dados; escrita e revisão do conteúdo do artigo, e aprovação da versão final publicada.

Author Contributions: The authors were responsible for the designing, delineating, analyzing and interpreting the data, production of the manuscript, critical revision of the content and approval of the final version published.

Conflitos de interesse: As autoras declararam não haver nenhum conflito de interesse referente a este artigo.

Conflict of Interest: None reported.

Orcid

Elisvania Nunes Braz

http://orcid.org/0000-0001-9440-4361

Nilsa Brito Ribeiro

http://orcid.org/0000-0001-9213-1726

Como citar este artigo / How to cite this article

APA

Braz, E. N., \& Ribeiro, N. B. (2018). A escrita de educandas do campo sobre sentidos da prática pedagógica em escolas do campo. Rev. Bras. Educ. Camp., 3(4), 1294-1315. DOI: http://dx.doi.org/10.20873/uft.2525-4863.2018v3n4p1294

ABNT

BRAZ, E. N.; RIBEIRO, N. B. A escrita de educandas do campo sobre sentidos da prática pedagógica em escolas do campo. Rev. Bras. Educ. Camp., Tocantinópolis, v. 3, n. 4 , set./dez., p. 1294-1315, 2018. DOI: http://dx.doi.org/10.20873/uft.2525-4863.2018v3n4p1294 